\title{
ANTIOXIDANT ACTIVITY OF FOURTEEN EULOPHIA SPECIES TRADITIONALLY KNOWN AS AMARKAND
}

\author{
AARTI NARKHEDE, MINAL MAHAJAN, ELANGBAM SINGH ${ }^{1}$, ABHAY HARSULKAR, SURESH JAGTAP* \\ Department of Herbal Medicine, Interactive Research School for Health Affairs (IRSHA), Bharati Vidyapeeth Deemed University, Pune- \\ Satara Road, Pune 411043, Maharashtra, India, ${ }^{1}$ Rajiv Gandhi Institute of Biotechnology, Bharati Vidyapeeth University, Pune Satara \\ Road, Pune 411046, Maharashtra \\ Email: chiritatml@rediffmail.com
}

Received: 13 May 2016 Revised and Accepted: 22 Jul 2016

\begin{abstract}
Objective: Amarkand is a group of medicinal plants, of which tubers are regularly consumed by the tribal people in India as food and medicine. It has a strong background of regional ethnopharmacological and food uses. Thus it can be effectively utilized as a source of natural antioxidants. The present study, of fourteen Eulophia species which are predominantly considered as "Amarkand", were focused for their antioxidant potential and polyphenolic content which facilitates the contribution of the traditional knowledge of plants from India.
\end{abstract}

Methods: Radical scavenging activity, ferric reducing antioxidant power and anti-lipid peroxidation assay were used to evaluate the antioxidant potential. In addition, total phenols, flavonoid and proanthocynidins were estimated.

Results: Results showed that all the studied amarkand species have promising antioxidant potential. Eulophia epidendrea (J. Koenig ex. Retz.) C. E. C. Fisch. (EE) and Eulophia mannii (Rchb. f.) Hook. f. (EM) had highest free radical scavenging potential among all. Eulophia epidendrea have highest ferric reducing potential which may be due to high flavonoid and proanthocyanidin content present.

Conclusion: The data clearly demonstrated that EE and EM may serve as a good natural antioxidant source against oxidative stress and related diseases.

Keywords: Eulophia, Amarkand, Antioxidant activity, Polyphenolic content

(C) 2016 The Authors. Published by Innovare Academic Sciences Pvt Ltd. This is an open access article under the CC BY license (http://creativecommons. org/licenses/by/4. 0/) DOI: http://dx.doi.org/10.22159/ijpps.2016v8i9.12801

Free radicals are any atom, molecule or ion containing one or more unpaired electrons in the outer orbital which are produced in the normal cellular metabolism. These radicals are mainly included reactive oxygen species (ROS) and reactive nitrogenous system (RNS) which constantly produced in the sub-cellular organelles of living cells and its overproduction can lead to damage biomolecules such as DNA, proteins and lipids [1]. Antioxidants are our vital defense against free radical induced damage. These compounds are associated with a reduction of excess load of free radicals and maintain a redox balance of the body, which is essential for its normal functions [2]. Plant and their products such as fruits, vegetables, grain cereals, etc. are rich in antioxidants. Previously it was reported and identified that more than 3100 antioxidantcontaining food, herbs, spices, beverages and supplements are regularly consumed by different cultures to decrease the oxidative stress and related cell damage [3]. Over the centuries, traditional medicines or folk medicines includes natural substances derived from plants for treatment of many diseases. These antioxidants are found to be responsible for several health benefits [4]. However, now a day's several plant's antioxidants are struggling to establish as sustainable nutraceuticals due to lack of quality control standards and also having confusion in the identification of exact plant species.

Amarkand is a group of medicinal plants, of which tubers are regularly consumed by the tribal people in India as a food and medicine. The word 'Amarkand' is commonly used for 30 plant species of Eulophia (Family-Orchidaceae) and Dioscorea bulbifera (Family-Dioscoraceae), out of these 21 species reported to possess food and medicinal values [5-7]. A study, on the lifestyle of the tribes in Maharashtra state, India, found that tribal people extensively use many species of amarkand as a major constituent in their diet [8]. Eulophia species reported to have various uses in Ayurveda such as astringent, digestive, expectorant, anabolic, tonic, diuretic, soft purgative [9]. These tubers are applied externally and given internally to cure disease. In northern India, especially in Punjab, tubers are used as a salep, which is considered as a general tonic [7]. Tribal people believe that these tubers would maintain their endurance under severe conditions in their daily life [10]. Thus, finding out authentic species of amarkand having highest potential is necessary for societal benefit. Tubers of these species are rich in all nutrients such as starch, free sugars, oils, proteins, phenols and also a good source of almost all elements [11]. In our earlier study, we have reported the anti-inflammatory, antimicrobial, antiglycation, and antioxidant properties of E. ochreata tubers [8, 12, 13]. It is evident that amarkand has exhibited both preventive and curative medicinal properties.

Recently, we have also investigated antioxidant potential of seven amarkand plants which includes six Eulophia species and $D$. bulbifera [6] and there is a need to study remaining amarkand species to know the best species among 21 . In the present study, fourteen species of Eulophia were collected and assessed for their polyphenolic content and antioxidant efficacy. This study can help to identify most bioactive amarkand species and to investigate their antioxidant potential.

All reagents were of analytical grade and distilled water was used throughout. Plants were identified by Dr. Suresh Jagtap (Senior Taxonomist, IRSHA, Pune). Fresh tubers of fourteen Eulophia species (Listed in table 1.) were collected from different locations of India. Collected tubers were cut into small pieces, shed dried and subjected to size reduction to course powder using mixer grinder. Extracts were prepared by soxhlet apparatus using methanol at $45^{\circ} \mathrm{C}$ for $6 \mathrm{~h}$ and subsequently evaporated to dryness under reduced pressure at $45^{\circ} \mathrm{C}$ in a rotary evaporator.

Polyphenolic content assays include determination of total phenol, flavonoid and proanthocynidin contents. Total phenolic content of extracts was assessed using known folin-ciocalteu method [14]. It is expressed as mg of gallic acid equivalents (GAE) per gram of dry weight. Total flavonoid content was determined using an aluminum chloride colorimetric method adapted from [15] and it is expressed as $\mathrm{mg}$ of quercetin equivalents. The assay was performed using vanillin method [16]. Results were expressed as mg equivalent to catechin. All the analysis was performed in triplicates. 
Free radical scavenging assays were used to determine the antioxidant capacity of amarkand extracts. Ferric reducing antioxidant power (FRAP) value was determined by modified method reported by [17]. Results were analyzed from the standard curve of ferrous sulphate and expressed in terms of $\mu \mathrm{M} \mathrm{Fe}$ (II)/g dry mass. Scavenging of nitric oxide capacity was measured spectrophotometrically using Griess reagent method [18]. In vitro
DPPH radical scavenging activity was determined by the method as described previously in [19]. In addition, the lipid peroxidation inhibition potential of extracts was analyzed by Thiobarbituric Acid Reactive Substances method described by [20]. Percent inhibition of free radicals was calculated and $\mathrm{IC}_{50}$ values were compared. The observations were replicated thrice for each parameter; mean values were pooled and standard deviation (SD) was calculated.

Table 1: Eulophia species studied from amarkand group

\begin{tabular}{lll}
\hline S. No. & Plant name & Location \\
\hline 1. & E. andamanensis Rchb. f. & Portblair (Andaman) \\
2. & E. bicallosa (D. Don.) Summerh. & West Sikkim (Sikkim) \\
3. & E. densiflora Lindl. & Nagaon (Assam) \\
4. & E. dufossei Guillaumin. & Patna (Bihar) \\
5. & E. epidendraea (J. Koenig ex. Retz.) C. E. C. Fisch. & Tirunelveli (Tamilnadu) \\
6. & E. explanata Lindl. & Junagadh (Gujrat) \\
7. & E. flava (Lindl.) Hook. f. & Nandurbar (Maharashtra) \\
8. & E. herbacea Lindl. & Thane (Maharashtra) \\
9. & E. kamarupa S. Chowdh. & Nagaon (Assam) \\
10. & E. mackinnonii Duthie. & Tawang (Arunachal Pradesh) \\
11. & E. mannii (Rchb. f.) Hook. f. & West Sikkim (Sikkim) \\
12. & E. obtusa (Lindl.) Hook. f. & Lakhimpur Kheri (Uttar Pradesh) \\
13. & E. promensis Lindl. & Sundarban (West Bengal) \\
14. & E. zollingeri (Reichb. f.) J. J. Sm. & West Kameng (Arunachal Pradesh) \\
\hline
\end{tabular}

Table 2: Total phenol, flavonoid and proanthocyanidin content in Eulophia species

\begin{tabular}{|c|c|c|c|}
\hline \multirow[t]{2}{*}{ Name of the plant } & $\begin{array}{l}\text { Total phenol content } \\
(50 \mu \mathrm{g} / \mathrm{ml} \text { conc. })\end{array}$ & $\begin{array}{l}\text { Total flavonoid content } \\
(1 \mathrm{mg} / \mathrm{ml} \text { conc. })\end{array}$ & $\begin{array}{l}\text { Total proanthocyanidin content } \\
(1 \mathrm{mg} / \mathrm{ml} \text { conc.) }\end{array}$ \\
\hline & mg/g of GAE equivalent ${ }^{a, b}$ & $\mathrm{mg} / \mathrm{g}$ of quercetin equivalent ${ }^{\mathrm{a}, \mathrm{c}}$ & $\mathrm{mg} / \mathrm{g}$ of catechin equivalent ${ }^{\mathrm{a}, \mathrm{d}}$ \\
\hline EA & $0.25 \pm 0.017$ & $0.06 \pm 0.007$ & $0.14 \pm 0.016$ \\
\hline $\mathrm{EB}$ & $0.23 \pm 0.021$ & $0.08 \pm 0.004$ & $0.16 \pm 0.038$ \\
\hline EDe & $0.53 \pm 0.001$ & $0.01 \pm 0.001$ & $0.03 \pm 0.003$ \\
\hline $\mathrm{EDu}$ & $0.78 \pm 0.003$ & $0.03 \pm 0.008$ & $0.12 \pm 0.010$ \\
\hline $\mathrm{EE}$ & $0.21 \pm 0.090$ & $0.63 \pm 0.003$ & $0.78 \pm 0.080$ \\
\hline EEx & $0.13 \pm 0.350$ & $0.51 \pm 0.026$ & $0.31 \pm 0.018$ \\
\hline $\mathrm{EF}$ & $0.31 \pm 0.078$ & $0.08 \pm 0.050$ & $0.41 \pm 0.038$ \\
\hline $\mathrm{EH}$ & $0.19 \pm 0.013$ & $0.05 \pm 0.002$ & $0.45 \pm 0.022$ \\
\hline EK & $0.41 \pm 0.081$ & $0.22 \pm 0.070$ & $0.29 \pm 0.019$ \\
\hline EMk & $0.29 \pm 0.014$ & $0.08 \pm 0.002$ & $0.31 \pm 0.056$ \\
\hline EM & $0.45 \pm 0.381$ & $0.39 \pm 0.018$ & $0.09 \pm 0.030$ \\
\hline $\mathrm{EOb}$ & $0.21 \pm 0.072$ & $0.31 \pm 0.190$ & $0.02 \pm 0.038$ \\
\hline EP & $0.29 \pm 0.003$ & $0.30 \pm 0.083$ & $0.07 \pm 0.010$ \\
\hline EZ & $0.51 \pm 0.075$ & $0.29 \pm 0.008$ & $0.31 \pm 0.090$ \\
\hline
\end{tabular}

aAll values are mean $\pm \mathrm{SD}, \mathrm{n}=3$, bValues are expressed as equivalent to gallic acid(mg/gram of GAE), cValues are expressed as equivalent to quercetin (mg/gram of quercetin), dValues are expressed as equivalent to catechin (mg/gram of catechin)

Table 3: FRAP activity and NO scavenging ability of Eulophia species

\begin{tabular}{lll}
\hline Name of the plant & FRAP assay (1 mg/ml conc.) & NO scavenging assay (500 $\boldsymbol{\mu g} / \mathbf{m l}$ conc.) \\
\cline { 2 - 3 } & $\boldsymbol{\mu M}$ Fe (II)/g of dry mass ${ }^{\mathbf{2}}$ & inhibition \\
\hline EA & $0.06 \pm 0.001$ & 11.02 \\
EB & $0.05 \pm 0.001$ & 15.32 \\
EDe & $0.01 \pm 0.001$ & 22.10 \\
EDu & $0.02 \pm 0.001$ & 16.82 \\
EE & $1.00 \pm 0.381$ & 41.12 \\
EEx & $0.79 \pm 0.090$ & 22.15 \\
EF & $0.32 \pm 0.082$ & 16.22 \\
EH & $0.07 \pm 0.006$ & 32.66 \\
EK & $0.65 \pm 0.018$ & 18.10 \\
EMk & $0.07 \pm 0.003$ & 29.10 \\
EM & $1.09 \pm 0.083$ & 23.16 \\
EOb & $0.31 \pm 0.190$ & 12.80 \\
EP & $0.09 \pm 0.005$ & 14.44 \\
EZ & $0.89 \pm 0.080$ & 32.80 \\
\hline
\end{tabular}

aAll values in FRAP assay are mean \pm SD and values are expressed as equivalent to Fe (II) ( $\mu \mathrm{M} / \mathrm{gram}$ of Fe (II)), n=3 
Plant polyphenols are the secondary metabolites; they show scavenging ability due to presences hydroxyl groups in their structures. These compounds are believed to be responsible for the antioxidant activity of plant [21]. Among plant phenolics, flavonoids are a major group of compounds which have potent antioxidant activities. Proanthocyanidins are condensed tannins, which help the body to remove free oxygen radicals from cells [22]. In the present study, all Eulophia species extracts showed the presence of polyphenols. Among 14 species, EDu, EZ and EM had highest phenolic content, whereas, EE was rich in flavonoids and proanthocyanidins as compared to other Eulophia species (table 2).

Reducing potential of antioxidant compounds present in the plants was measured by FRAP method. This method is directly related to the total antioxidant activity of hydrogen donating compounds present in the extracts. FRAP value was analyzed at $593 \mathrm{~nm}$ by monitoring the formation of intense blue colored ferrous tripyridyl triazine (Fe (II)-TPTZ) complex [23]. In the study, EM and EE were shown highest FRAP value which is $1.09 \pm 0.083$ and $1.00 \pm 0.381$ respectively than other species (table 3 ). This data suggests that EM and EE extracts have highest ferric reducing power which indicates their ability to donate an electron.

Endothelial cells, macrophages, neurons, etc. generate nitric oxide (NO) which is an important chemical mediator involved in many physiological processes especially in the pathogenesis of inflammation. Under aerobic conditions, NO is very unstable and reacts with oxygen to produce intermediates which is highly toxic to humans [24]. The present study showed that the methanol extract of EE had highest inhibition activity of $41.12 \%$, followed by EZ and EH having inhibition of $32.80 \%$ and $32.66 \%$, respectively than other Eulophia species at concentration $500 \mu \mathrm{g} / \mathrm{ml}$ (table 3). Thus, EE may have the property to counteract the ill effects of excessive nitric oxide generation.

DPPH is nitrogen-centered, stable free radical, which can get readily destroyed by free radical quencher and shows a strong absorption band at $517 \mathrm{~nm}$. The decrease in optical density of plant samples indicates its antioxidant activity [25]. Results revealed that EE and EM extracts had (IC 50 value of $32 \pm 0.5,57.2 \pm 0.9$ respectively) highest ability to scavenge DPPH free radical than other Eulophia species (fig. 1). These results suggest that EE and EM contain more hydrogen donor compounds to free radicals, which removes an odd electron.

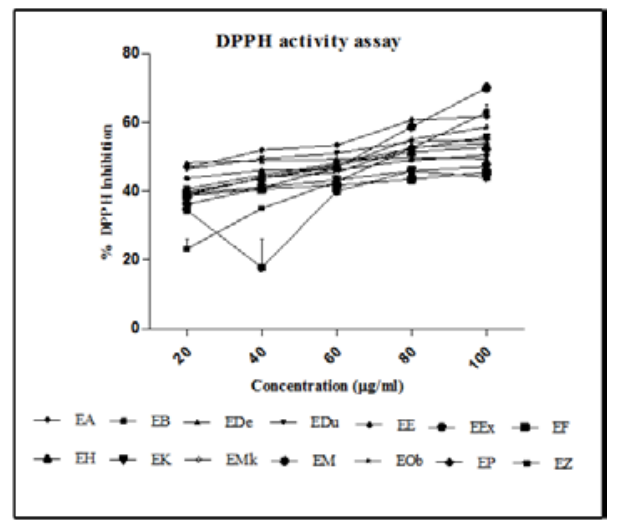

Fig. 1: DPPH scavenging activity of Eulophia species

Anti-lipid peroxidation assay was performed using Thiobarbituric acid reactive substances (TBARS) method using goat liver for lipid source [26]. Lipid peroxidation refers to the oxidative deterioration of lipids, mainly by the effect of different ROS. In this method, polyunsaturated fatty acids get oxidized and react with thiobarbituric acid to give malonaldehyde (MDA) in the form of pink chromogen [27]. Results revealed that all Eulophia species had shown anti-lipid peroxidation effect, but EMk, EE and EDu showed highest inhibition of peroxidation than other species which indicates their potential against oxidative stress (fig. 2). This activity against peroxidation by amarkand species justifies their traditional use, against inflammation.

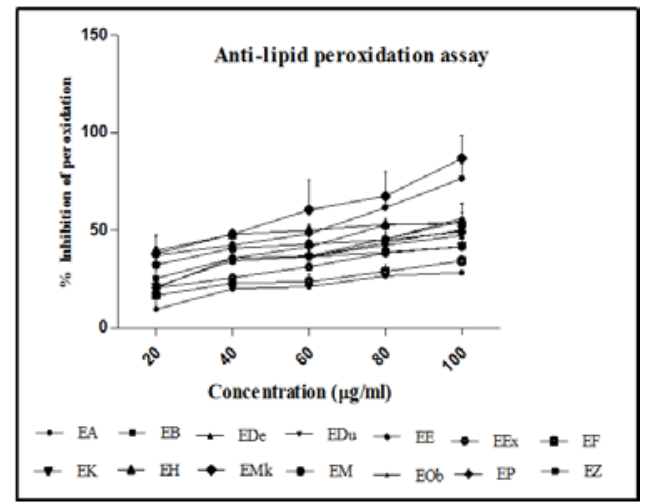

Fig. 2: Anti lipid peroxidation potential Eulophia species

In literature, medicinal properties in terms of ethnobotany and pharmacology have been reported only for 20 out of 32 known Eulophia species. Among the 20 species, six species have been proved to possess antioxidant activity [6]. In the present study, we have found that all investigated members of Eulophia have better antioxidant potential, but among them Eulophia epidendrea and Eulophia mannii possesses significant potential for scavenging free radical. Both these species revealed the presence of compounds like phenols, flavonoids, proanthocyanidins. Among both of these species, EE had highest ferric reducing potential and possess marked anti-lipid peroxidation potential. Eulophia epidendrea tubers possess high antioxidant potential which may be directly proportional to its polyphenolic content, and this activity may be contributed by the presence of sterols, triterpene and triterpenoids as reported previously [28]. Further, in vivo work is warranted to support our findings and conclusions, which bring a new natural product into cosmetic, food production and pharmaceutical industries.

\section{ACKNOWLEDGEMENT}

Authors are thankful to Department of Science and Technology (DST), India for the research grant of this work.

\section{CONFLICT OF INTERESTS}

The authors declare that there is no conflict of interests.

\section{REFERENCES}

1. Sutar RC, Kalaichelvan VK. Evaluation of antioxidant activity of leaf extracts of Holoptelea integrifolia (Roxb) planch. Int J Appl Pharm 2014;6:6-8.

2. Kasote DM, Katyare SS, Hegde MV, Bae H. Significance of antioxidant potential of plants and its relevance to therapeutic applications. Int J Biol Sci 2015;11:982-91.

3. Sen S, Chakraborty R. The role of antioxidants in human health in oxidative stress: diagnostics, prevention, and therapy. ACS Symposium Series. Vol. 1083. Chapter 1; 2011. p. 1-37.

4. Gupta VK, Sharma SK. Plants as natural antioxidants. Indian J Nat Prod Resour 2006;5:326-34.

5. Jagtap SD, Deokule SS, Pawar PK, Harsulkar AM. Traditional ethnomedicinal knowledge confined to the pawra tribe of Satpura Hills, Maharashtra, India. Ethnobotanical Leaflets 2009;13:98-115.

6. Narkhede AN, Jagtap SD. Screening of amarkand species with respect to their polyphenolic content and free radical quenching potential. Int J Pharm Biol Sci 2015;6:1122-33.

7. Narkhede AN, Kasote DM, Kuvalekar AA, Harsulkar AH, Jagtap SD. Amarkand: a comprehensive review on its ethnopharmacology, nutritional aspects, and taxonomy. J Intercult Ethnopharmacol 2016;5:198-204.

8. Jagtap SD, Gilda S, Bhondave P, Paradkar A, Pawar P, Harsulkar A. Validation of the potential of Eulophia ochreata tubers for 
anti-inflammatory and antioxidant activity. Pharmacologyonline 2009;2:307-16.

9. Vaidya B. Nighantu Adarsha, Chaukhamba Bharati Academy, Varanasi, India; 2004.

10. Narkhede AN, Jagtap SD, Nirmal PS, Giramkar SA, Nagarkar BE Kulkarni OP, et al. Anti-fatigue effect of amarkand on endurance exercise capacity in rats. BMC Complementary Altern Med 2016;16:23-7.

11. Aberoumand A, Deokule SS. Determination of elements profile of some edible wild plants. Food Anal Methods 2009;2:116-9.

12. Devkar S, Jagtap SD, Kale Y, Kasote D. Antibacterial activity of Eulophia ochreata L. tubers. J Herb Med Toxicol 2009;3:31-3.

13. Narkhede A, Nirmal P, Tupe R, Kulkarni O, Harsulkar A, et al. In vitro antioxidant, antiglycation, and a-amylase inhibitory potential of Eulophia ochreata L. J Pharm Res 2012;5:2532-7.

14. Singleton VL, Rossi JA. Colorimetry of total phenolics with phosphomolybdic-phosphotungstic acid reagents. Am J Enol Vitic 1965;16:144-58.

15. Khan RA, Khan MR, Sahreen S, Ahmed M. Evaluation of phenolic contents and antioxidant activity of various solvent extracts of Sonchus asper Hill. Chem Cent J 2012;6:1-7.

16. Igbinosa FO, Chigor V, Uzunuigbe O, Oyedemi S, Odjadjare EE, Okoh AI, et al. Polyphenolic content and antioxidant potential of stem bark extracts from Jatropha curcas (Linn). Int J Mol Sci 2011;12:2958-71.

17. Benzie IFF, Strain JJ. The reducing ability of plasma as a measure of antioxidant power-the FRAP assay. Anal Biochem 1996;239:70-6.

18. Sreejayan N, Rao MNA. Nitric oxide scavenging activity by curcuminoids. J Pharm Pharmacol 1997;47:105-7.

19. Kikuzaki H, Nakatani N. Antioxidant effect of some ginger constituents. J Food Sci 1993;58:1407-10.

20. Ohkawa H, Ohishi N, Yagi K. Assay for lipid peroxide in animal tissues by the thiobarbaturic acid reaction. Anal Biochem 1979;95:351-8.
21. Rahman H, Manjula K, Aanoosha T, Nagaveni M. Eswaraiah C, Bardalai D. In the vitro antioxidant activity of Citrullus lanatus seed extracts. Asian J Pharm Clin Res 2013;6:152-7.

22. Narkhede A, Gill J, Thakur K, Singh D, Singh E, Kulkarni O, Harsulkar A, et al. Total polyphenolic content and free radical quenching potential of Dioscorea alata L. tubers. Int J Pharm Pharm Sci 2013;5:866-9.

23. Ghasemzadeh A, Jaafar ZE, Rahmat A. Antioxidant activities, total phenolics and flavonoids content in two varieties of malaysia young ginger (Zingiber officinale Roscoe). Molecules 2010;15:4324-33.

24. Aiyegoro OA, Okoh AI. Preliminary phytochemical screening and in vitro antioxidant activities of the aqueous extract of Helichrysum longifolium DC. BMC Complementary Altern Med 2010;10:1-8.

25. Mohana M, Padma PR. Ffree radical scavenging activity of the bacoside fraction from Bacopa monnieri. Int J Curr Pharm Res 2016;8:61-4.

26. Giramkar S, Kulkarni O, Ligade G, Narkhede A, Mukherjee S, Takle $S$, et al. Effect of pre-sterilization on physicochemical parameters and in vitro free radical scavenging potential of Saraswatarishta. J Pharm Res 2012;5:2657-63.

27. Halliwell B, Chirico S. Lipid peroxidation: its mechanism, measurement, and significance. Am J Clin Nutr 1993;57(Suppl 5):715S-25S.

28. Maridass $M$, Ramesh $U$. Investigation of phytochemical constituents from Eulophia epidendraea. Int J Biol Technol 2010;1:1-7.

\section{How to cite this article}

- Aarti Narkhede, Minal Mahajan, Elangbam Singh, Abhay Harsulkar, Suresh Jagtap. Antioxidant activity of fourteen Eulophia species traditionally known as amarkand. Int J Pharm Pharm Sci 2016;8(9):313-316. 